\title{
Psychological Interventions for Well-Being in Healthy Older Adults: Systematic Review and Meta-Analysis
}

\author{
Suguru Iwano ${ }^{1}$ (D) $\cdot$ Kohei Kambara ${ }^{1} \cdot$ Shuntaro Aoki ${ }^{1}$
}

Accepted: 4 January 2022 / Published online: 21 January 2022

(c) The Author(s) 2022

\begin{abstract}
Aging societies are a global problem, necessitating the promotion of well-being in healthy older adults. However, the evidence regarding psychological interventions in this population is unclear. Therefore, we conducted a systematic review and metaanalysis to clarify the effects of psychological interventions on the well-being of healthy older adults. A systematic literature search was performed using PubMed, PsycINFO, and CiNii. Included studies were randomized controlled trials of psychological interventions designed to improve psychological well-being in healthy older adults. The search yielded 1,047 articles, out of which five qualitative and four quantitative studies were selected. A meta-analysis was performed using a random effects model. We found a large effect size (Hedges' $\mathrm{g}=0.87$ ) and heterogeneity among the studies ( $\mathrm{I} 2=94.4 \%, \tau 2=0.556, p=0.00$ ). Most studies were evaluated as being of a low quality. There were five types of interventions: an isolation prevention program, outdoor activities, art therapy through participating in theater workshops, animal-assisted activity, and an encounter group. The results indicated that healthy older adults' psychological well-being can be promoted through interventions. The evaluated studies had no theoretical commonality; however, all research involved interaction with other people or animals. Thus, we recommend increased interaction with people or animals to promote well-being in older adults. Heterogeneity is a limitation of the study, and there is a need for more high-quality studies on well-being in healthy older adults.
\end{abstract}

Keywords Well-being $\cdot$ Healthy older adult $\cdot$ Psychological intervention $\cdot$ Systematic review

\section{Introduction}

Aging societies are a global problem. The World Health Organization (WHO) defines an aging society as one where at least $7 \%$ of the population is 65 years and older (United Nations, 1956). As of $2020,9.3 \%$ of the world's population is 65 years and older, with Japan, at $28.6 \%$, having the highest aging rate (United Nations, 2020). By 2050, 16.2\% of the global population

Suguru Iwano

iwano-suguru@oita-u.ac.jp

Oita University, Oita, Japan 
is projected to be aged 65 years and over (United Nations, 2020), which will be of particular concern in Europe, North America, and Australia.

Although there are many psychosomatic problems associated with older age, psychological health is particularly important (Alexopoulos, 2005). In later life, the incidence of dementia is a concern; however, there are other problems as well, such as loneliness and the risk of suicide (Wiktorsson et al., 2010). Various intervention studies have been conducted on these physical and psychological issues (Pinquart et al., 2007). In particular, medical and biological research has focused on the prevention of and rehabilitation after physical illness. However, since physical problems associated with aging are inevitable, we should also consider the psychological and social aspects of health. Therefore, promoting well-being is considered important, as it is a health aspect that is less susceptible to biological influences in older age (Cho et al., 2015).

Well-being is a state in which an individual can realize his or her own abilities, cope with normal life stressors, work productively, and make a positive contribution to the community (WHO, 2013). Well-being, by definition, considers the positive aspects of mental health rather than the presence or absence of illness or the magnitude of mental health symptoms. In this paper, we will discuss the role of well-being in the health of the elderly in terms of bio-psycho-social aspects. From a psychological point of view, well-being is known to likely increase in older adults, despite their reduced physical function (Blanchflower \& Oswald, 2008). People with high levels of well-being have been shown to have low rates of suicide and depression (Bray\& Gunnell, 2006), and increasing psychological well-being in older age is a viable preventive measure. On the biological side, psychological adaptation in older adults affects activity levels (Sin \& Lyubomirsky, 2009) illness risk (Strawbridge et al., 2002). For example, older adults with better well-being are more likely to engage in healthy behaviors (LawlerRow \& Piferi, 2006) and have better recovery after physical illness (Lamers et al., 2012). In terms of social aspects, older adults with better well-being have wider social networks and better friendships (Pinquart \& Sörensen, 2000). Therefore, from the perspective of the biopsycho-social model, the well-being of the elderly is important. In addition, it should be noted that well-being differs from quality of life (QOL) in that it does not include negative indicators. Therefore, well-being is considered a suitable indicator of health promotion and primary prevention in healthy people.

It is necessary to consider age-specific factors that promote well-being in older adults. Psychological interventions have been reported to be effective in this regard. According to systematic reviews, mindfulness, life review, and well-being therapy, as well as other psychological interventions, improve well-being (Bolier et al., 2013; Sin \& Lyubomirsky, 2009). However, it has also been shown that the components of well-being differ between older adults and younger people (Iwano et al., 2014). Older and younger adults have different characteristics related to mental health disorders, such as depression (Gallo et al., 1994). However, owing to the limited number of studies on older adults, sub-analyses on the matter are yet to be performed (Bolier et al., 2013). Therefore, it is currently unclear what kind of intervention is effective and what magnitude of mental health-related effects can be expected.

\section{The Present Study}

Considering these arguments, improving well-being in older adults is meaningful, both in terms of health promotion based on the bio-psycho-social model, and depression and suicide prevention. Particularly, given the aging of the global population, it is necessary to promote well-being in older adults rather than focusing solely on disease prevention. 
However, there are still some problems that need to be addressed. First, the number of intervention studies performed on older adults has not been clarified. Previous studies do not show the accumulation of high-quality evidence because well-being intervention studies are mostly conducted on adolescents and younger adults (e.g., Sin \& Lyubomirsky, 2009). Second, the intervention methods for older adults are not organized. Factors influencing well-being are not uniform across age groups (Iwano et al., 2014). At present, because of the lack of age-specific research, it is not clear which interventions are effective for older adults. Third, the effects of intervention studies on older adults' well-being have not been clarified. Interventions to enhance well-being have different effects depending on the age of the target population (Sin \& Lyubomirsky, 2009), but the paucity of studies in the elderly has not clarified the mechanism and extent of the influence. Therefore, we do not have adequate information on evidence-based practice. Furthermore, from the health promotion and prevention viewpoint, the effects of interventions on healthy individuals are important. However, most studies on older adults are related to dementia or illnesses, and a systematic review of healthy older adults has not been conducted. Therefore, it is necessary to organize the current research to consider psychological interventions for older adults.

In this study, we conducted a systematic review and meta-analysis to examine whether a psychological approach can affect the well-being of healthy older adults. A systematic review is a research method that aggregates multiple studies according to specific criteria to provide high-quality evidence (Higgins, 2008). Although there are limitations such as publication bias and file-drawer problems, it is recommended to use meta-analyses to clarify the effects of integrating multiple research findings because of the lack of testing power and the fact that results may differ among studies (Cristea et al., 2015). In particular, not only can conducting a systematic review in a research area that one has not been performed provide evidence for the current state of the art, but can also contribute to identifying research problems and suggesting the need for research. In this way, it is possible to organize studies on psychological approaches for older adults in the current aging society and clarify the kind of research needed in the future.

\section{Methods}

This systematic review was conducted in accordance with the Preferred Reporting Items for Systematic Reviews and Meta-Analysis (PRISMA) guidelines (Moher et al., 2009).

\subsection{Search Strategy}

From February 27, 2018, we searched PubMed, PsycINFO, and CiNii using the search terms "older*," "elder*," "late-life," "geriat*," "well-being," and "wellbeing". Additionally, secondary searches (hand searches) were performed when a source cited relevant data in other paper-based studies. Scientific articles were selected from the aforementioned databases for the period from January 1987 to November 2017. A total of 1,047 articles were extracted. The first author performed this search.

\subsection{Inclusion and Exclusion Criteria}

Our inclusion criteria for studies to be evaluated were as follows: (1) written in English or Japanese, (2) randomized controlled trials (RCTs), (3) based on healthy participants aged 
65 years or older, (d) psychological approach to the intervention, (4) well-being measured as an outcome, (5) published in a peer-reviewed journal, and (6) description of statistics needed to calculate effect sizes. We extracted papers based on the definition of older adults as people aged 65 and over (United Nations, 1956). In addition, because the employment rate declines significantly at and after the age of 65 (International Labour Organization, 2021), we considered that the lifestyles of people aged 65 and older may be different from those of people aged 60. Employment status has also been shown to affect well-being in old age, particularly for those 65 years and older (Warr et al., 2004). Therefore, in this study, the participants were aged 65 years or older. In the present study, a "psychological approach" was defined as efforts to improve well-being through modification of behavior, cognition, or emotion. Studies that aimed to improve well-being by directly manipulating anatomical and/or physiological processes (e.g., medication, massage therapy, and exercise therapy) were excluded (Miller \& Cohen, 2001). While this psychological approach did not include direct physical intervention methods, such as physical rehabilitation and social work interventions, it covered studies whose purpose was to manipulate psychological variables, such as decreasing avoidance behavior and increasing approach behavior, through activity. The concept of well-being employed was based on Wright and Cropanzano's (2000) study, which indicated that in terms of the individual psychological function, and more specifically on the basis of the circumplex model of emotion, psychological well-being measures the hedonic or pleasantness dimension of individual emotions. In general, well-being refers to overall health and includes multiple elements, such as positive emotions, negative emotions, and QOL. However, positive and negative emotions are different concepts and have completely different psychological functions. Positive emotions have been shown to occur even in high-stress situations (Folkman, 1997), and the neural circuits that activate positive and negative emotions are different (Witvliet \&Vrana, 1995). Therefore, we excluded indices that measured negative aspects, such as pain and depression. Further, participants were identified as healthy when: (1) they had no diagnosis of mental or physical illness and (2) the inclusion criteria of the individual studies did not specify that high-risk factors for mental and physical health problems, such as frailty and isolation, were prominent.

\subsection{Literature Search}

After excluding 67 duplicates, two authors (SI and KK) independently screened the remaining 980 papers based on the eligibility criteria. Screened papers were categorized as "qualified," "excluded," or "unknown." In the first screening, 763 papers were excluded. When evaluations by the two authors did not match, another author (SA) performed the evaluation independently to confirm eligibility and consulted with the other authors when in doubt. Ultimately, five papers were extracted for review (Fig. 1). If no statistics were provided in the paper, the first author was contacted by the researchers via email or a social networking service.

\subsection{Evaluating Risk of Bias}

The Cochrane Collaboration tool for assessing risk of bias (CCAR; Higgins \& Green, 2008) was used to assess study quality. Our choice in this is based on the fact that it is a highly transparent assessment tool developed by a working group of the Cochrane Collaboration and that it has been published in detail (see Higgins \& Green, 2008). The CCAR 


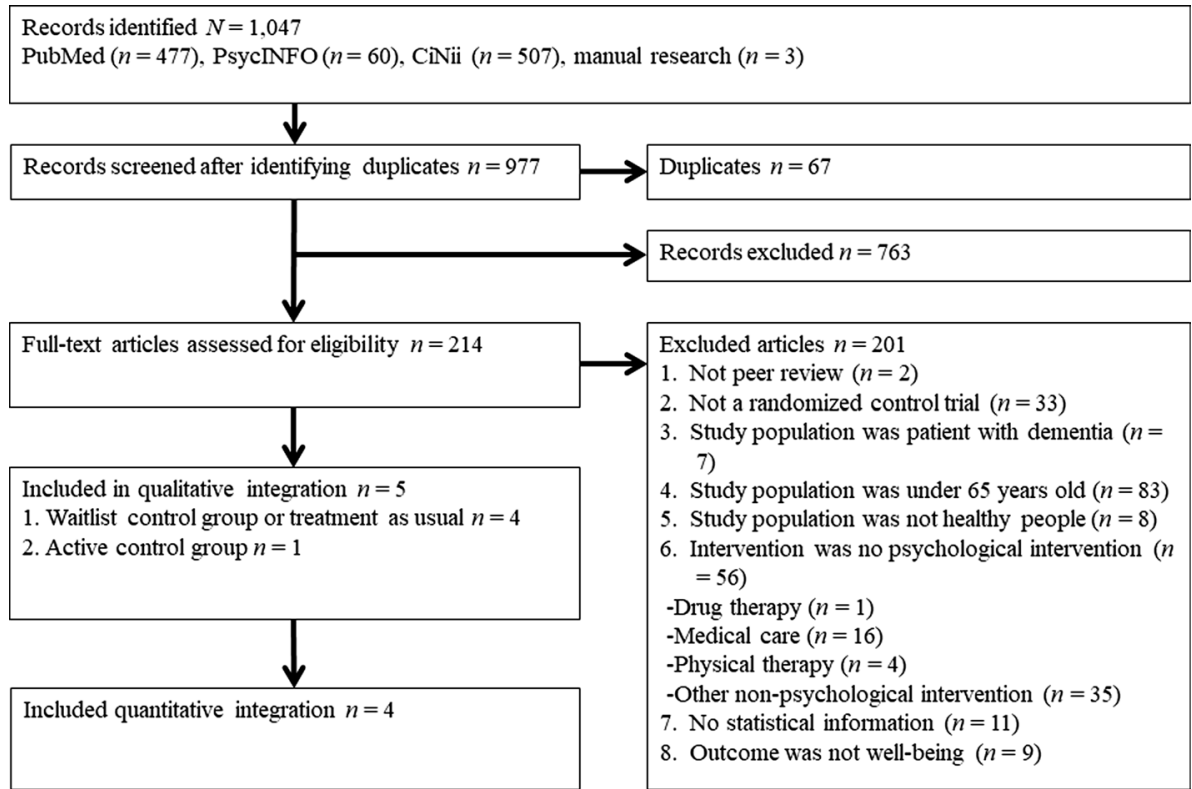

Fig. 1 Flow diagram of literature search in the study. We performed the following steps at screening: eliminate duplicated studies, read abstract and check inclusion and exclusion criteria, read full text and check inclusion and exclusion criteria, choose studies for qualitative integration, and choose studies for quantitative integration

can assess the quality of a study on six criteria: sequence generation, allocation concealment, blinding of participants, incomplete outcome data, selective outcome reporting, and other potential threats to validation. Because systematic reviews integrate multiple studies, there is a strong need to assess and present the risk of bias (Higgins \& Green, 2008). For each study, two of the authors (SI and KK) independently rated each of the CCAR domains as "high quality," "low quality," or "unknown." When studies were evaluated as having a low risk of bias, we determined them to be of high quality, indicated by "yes," and when they were evaluated as having a high risk of bias, we determined them to be of a low quality, indicated by "no." If studies did not provide enough information, we declared them "unclear." Items for which the evaluators had differing opinions were checked and evaluated again. Using the CCAR, we were able to determine the level of risk of bias in the articles used in this study. The advantage of using CCAR is that it allows us to examine the risk of bias without subjectivity. However, even when CCAR is used, the risk of bias cannot be completely eliminated, which necessitates careful peer review by researchers (Jørgensen et al., 2016) (Table 1).

\subsection{Coding and Calculation of Effect Sizes}

From each paper, we extracted the participant characteristics, group settings, intervention methods, number of sessions, type of outcome measures, and measurement results for the outcome. Intervention content was judged to be highly heterogeneous because participant attributes, intervention methods, and outcome indices varied widely. Generally, when the 


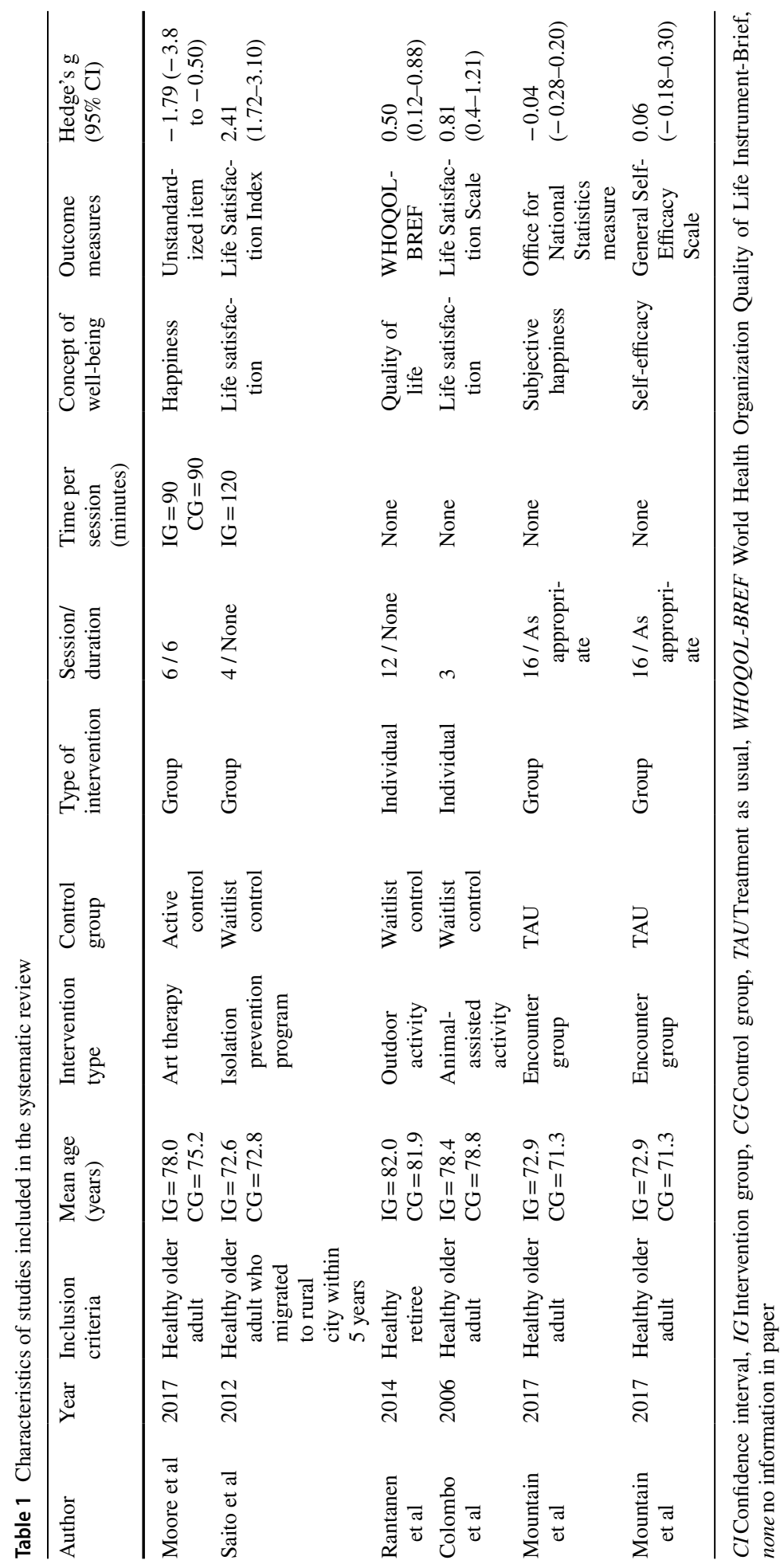


data are homogeneous, the effect size can be calculated using fixed effects; however, when the data are highly heterogeneous, it is difficult to estimate the exact value. Therefore, in our case, a random-effects model was used to calculate the effect size. The effect size was calculated using Hedges' $g$, and the $95 \%$ confidence intervals were calculated. When the difference between the means of the two groups is used as the effect size, Hedges' $g$ is calculated using an invariant estimator, which is more suitable as an inferential effect size than Cohen's $d$ (Hedges, 1981). Therefore, a random effects model was used to calculate effect size using $\mathrm{R}$ version 3.6.1 (https://www.r-project.org/) (Conducting meta-analyses in $\mathrm{R}$ with the metafor (10.18637/jss.v036.i03)). For effect size, Hedges' $g$ and 95\% confidence intervals (CIs) were calculated (Hedges, 1981). If two well-being indices were used in one study, the data were integrated using the following equation according to Yokomitsu et al. (2014) $(N=$ sample size, $\mathrm{M}=$ mean, $\mathrm{SD}=$ standard deviation $)$ :

$$
\begin{gathered}
\text { Sample size }=N_{1}+N_{2} \\
\text { Mean }=\frac{\left(N_{1} M_{1}+N_{2} M_{2}\right)}{N_{1}+N_{2}} \\
\text { Standard deviation }=\sqrt{\frac{\left(N_{1}-1\right) S D_{1}^{2}+\left(N_{2}-1\right) S D_{2}^{2}+\frac{N_{1} N_{2}}{N_{1}+N_{1}}\left(M_{1}+M_{2}-2 M_{1} M_{2}\right)}{N_{1}+N_{2}-1}}
\end{gathered}
$$

\section{Results}

\subsection{Study Quality}

As a result of the search, 1,047 papers were extracted, 214 papers were carefully read, and five papers were ultimately analyzed. Table 2 lists the quality of the evaluated studies. The average of items rated "high quality (Y)" was 1.80 per paper. Only one study (Mountain et al., 2017) was evaluated as "high quality" in five of the six items; however, only two of the items (sequence generation in Rantanen et al. (2014) and incomplete outcome data in Colombo et al. (2006)) were evaluated as "high quality" in four studies. By item, the determination of "yes" was made for $40 \%$ of the papers for sequence generation, blinding of participants, and incomplete outcome data. However, for allocation concealment, selective outcome reporting, and other potential threats to validity, $20 \%$ of the papers were categorized as "yes," and only one paper was judged to be of "high quality".

\subsection{Participant Characteristics}

Of the five evaluated studies, one concerned people who had just moved to a new city, and the intervention therein involved an isolation prevention program. One focused on planning and executing outdoor activities on a one-on-one basis for retired people. The other three did not include any attributes in the inclusion criteria, except that they were healthy participants. For art therapy and outdoor activities, the inclusion and exclusion criteria were set in detail, and the criteria for acceptance were that there were no problems with participants' cognitive, mental, or physical functions. 
Table 2 Quality of studies

\begin{tabular}{lllllll}
\hline Author & $\begin{array}{l}\text { Sequence } \\
\text { generation }\end{array}$ & $\begin{array}{l}\text { Allocation } \\
\text { concealment }\end{array}$ & $\begin{array}{l}\text { Blinding of } \\
\text { participants }\end{array}$ & $\begin{array}{l}\text { Incomplete } \\
\text { outcome data }\end{array}$ & $\begin{array}{l}\text { Selective } \\
\text { outcome } \\
\text { reporting }\end{array}$ & $\begin{array}{l}\text { Other potential } \\
\text { threats to valid- } \\
\text { ity }\end{array}$ \\
\hline Moore et al & $\mathrm{U}$ & $\mathrm{N}$ & $\mathrm{N}$ & $\mathrm{N}$ & $\mathrm{U}$ & $\mathrm{N}$ \\
Saito et al & $\mathrm{U}$ & $\mathrm{N}$ & $\mathrm{N}$ & $\mathrm{N}$ & $\mathrm{U}$ & $\mathrm{N}$ \\
Rantanen et al & $\mathrm{Y}$ & $\mathrm{U}$ & $\mathrm{U}$ & $\mathrm{N}$ & $\mathrm{U}$ & $\mathrm{N}$ \\
Colombo et al & $\mathrm{U}$ & $\mathrm{U}$ & $\mathrm{U}$ & $\mathrm{Y}$ & $\mathrm{U}$ & $\mathrm{N}$ \\
Mountain et al & $\mathrm{Y}$ & $\mathrm{N}$ & $\mathrm{Y}$ & $\mathrm{Y}$ & $\mathrm{Y}$ & $\mathrm{Y}$ \\
\hline
\end{tabular}

$\mathrm{Y}=$ Yes (low risk of bias), $\mathrm{N}=\mathrm{No}$ (high risk of bias), $\mathrm{U}=\mathrm{Unclear}$ (unknown)

\subsection{Psychological Intervention Types}

Intervention content varied widely; no two studies used the same intervention. The intervention types were an isolation prevention program (Saito et al., 2012), outdoor activities (Rantanen et al., 2014), art therapy through participation in theater workshops (Moore et al., 2017), animal-assisted activity (Colombo et al., 2006), and an encounter group (Mountain et al., 2017).

Three of the five interventions were group-based, and two studies provided individual interventions. Group interventions included elements that strengthened cooperative relationships with others, such as migrants to local cities, practicing theater in a group, and strengthening roles and relationships within the community. Outdoor activities with an instructor and animal-assisted activities were also similar to group interventions in terms of interacting with animals or other people.

There was no uniformity in the duration or number of sessions, ranging from a minimum of four sessions and a maximum of 16 sessions. The time spent per session was not described in three of the five papers.

\subsection{Outcome Types}

Outcome measures for well-being included five types of standardized measures and one non-standardized item (Table 1). Mountain et al. (2017) used two types of wellbeing measure. Two studies measured satisfaction and happiness. QOL and self-efficacy were measured in one study. However, different measurements were used in all five studies. For satisfaction, the Life Satisfaction Index (Neugarten et al., 1961) and the Life Satisfaction Scale (De Leo et al., 1995) were used, and for happiness, the Office for National Statistics (Tinkler \& Hicks, 2011) and non-standardized measurement indicators were used. Additionally, the WHO QOL-Brief (Skevington et al., 2004) was used for QOL, and the General Self-Efficacy Scale (Schwarzer \& Jerusalem, 1995) was used to assess self-efficacy. Although the concept of measurement was common in terms of positive individual psychological aspects, the definition of well-being in each study was determined to be vague and inconsistent. 


\subsection{Effect Size}

Quantitative integration was performed to examine the effects of various interventions. Only Moore et al. (2017) used an active control group, while the other four studies used either a waitlist or treatment as usual (TAU). It is problematic to mix active control groups and waitlist or TAU groups for quantitative convenience. Therefore, a meta-analysis was performed in four papers (Colombo et al., 2006; Mountain et al., 2017; Rantanen et al., 2014; Saito et al., 2012).

Figure 2 shows the results of calculating the effect size. Psychological intervention was judged to have a higher positive effect on well-being and a greater effect size than the control condition (Hedges' $g=0.87,95 \% \mathrm{CI}=0.11$ to 1.63 ). Statistical heterogeneity was judged to be high $\left(I^{2}=94.4 \%, \tau^{2}=0.556, p=0.01\right)$.

Next, we examined the four studies for publication bias. The funnel plot is shown in Fig. 3, and based on its shape, publication bias was considered to be large.

\section{Discussion}

In this study, we conducted a systematic review to examine whether a psychological approach targeting healthy older adults can affect well-being. The reason for the small number of eligible papers is that many of the studies did not correspond to the outcome measure of well-being: many of the studies were conducted on subjects under 65 years of age, and few of the studies used RCTs. In particular, the originality of this study is that the outcome measure was well-being, rather than a negative measure such as depression. Therefore, the number of papers that met the criteria was small. Five studies were qualitatively integrated, and four studies were quantitatively integrated. The procedure of this study was to first evaluate the effects of intervention studies on well-being, then systematically organize types of intervention studies, and finally clarify the number of published studies targeting healthy older adults.

\subsection{Effects of the Psychological Approach}

First, we verified the effects of intervention studies aimed at improving the well-being of healthy older adults. Our meta-analysis revealed that a psychological approach generally produces a large effect size. In this study, Hedges' $g$ was 0.87 , which is large compared to other studies. For example, in a meta-analysis with well-being as an outcome, the effect size of positive psychological interventions in healthy adults was Hedges' $g=0.17$ (95\% $C I=0.08-0.25$; Bolier et al., 2013), and the effect size of physical activity was Hedges'

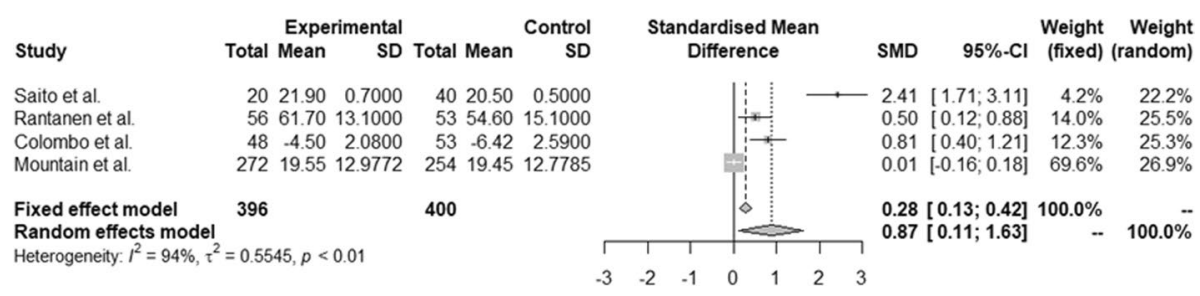

Fig. 2 Effect size and statistical information 


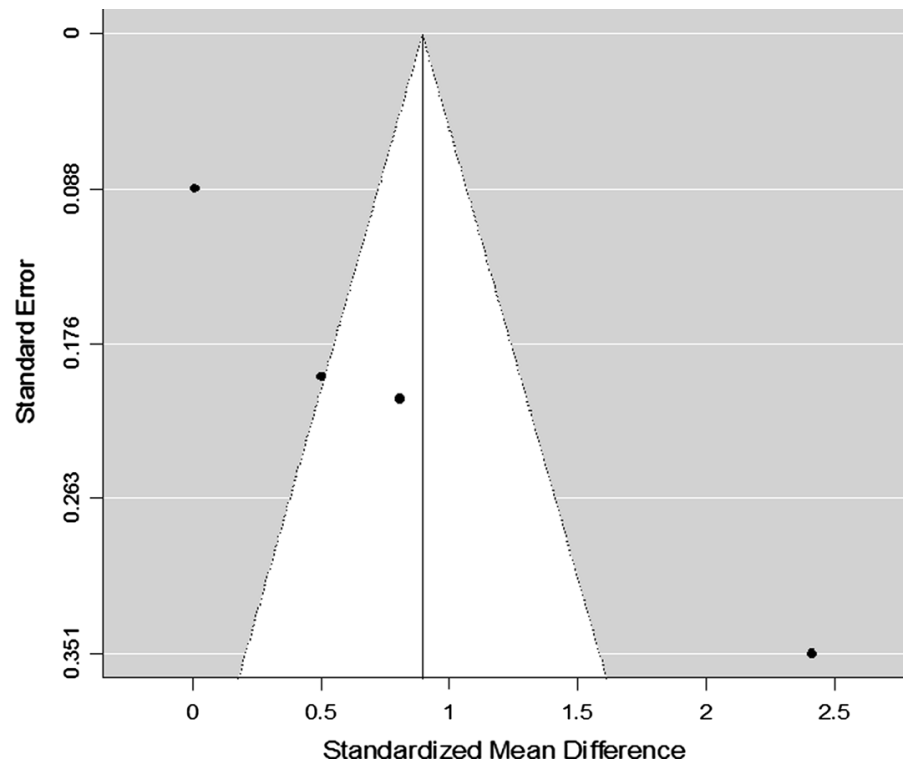

Fig. 3 Funnel plot of publication bias

$g=0.37$ (95\% CI $=0.15-0.59$; Netz et al., 2005). Therefore, a psychological approach is considered useful for improving the well-being of healthy older adults. Improvements in well-being are considered to promote successful aging in healthy older adults. In older age, there are many negative changes in experiences such as reduced physical function (Garber et al., 2010) and the loss of close others (Onrust et al., 2007). Therefore, it is important to promote psychological adjustment, and for that reason, psychological approaches are considered effective in promoting psychological adjustment and well-being, and preventing mental problems in older adults.

\subsection{Study Features and Quality}

In this study, we extracted five types of intervention methods from five papers. The interventions included a loneliness prevention program, art therapy, an encounter group, and individual interventions using outdoor or animal-assisted activities. There were no theoretically common interventions among the selected studies. Of course, group intervention involves collaboration with other participants, and especially in the isolation prevention program and encounter group, the aim was to share experiences and strengths among participants and strengthen relationships between participants. Even in the individual interventions, participants worked closely with an instructor for outdoor activities or took care of the animals. Since all research involved interaction with other people or animals, increasing interpersonal interaction seemed to be a common factor. Although not all studies clearly indicated that the interaction was a core factor for promoting well-being, the findings of this study suggest that all studies aimed to include increasing interpersonal interaction and social support. Isolation has been reported as a common psychological concern in older adults, and psychosocial interventions for isolation have been shown to be effective. In a systematic review (Dickens et al., 2011), group psychological interventions 
were shown to be beneficial for socially isolated older adults by enabling them to make new friends, reduce depression, and increase activity. The results of our study suggest that interventions for older adults that increase their opportunities for interaction are likely to enhance well-being.

Owing to the high heterogeneity of the evaluated research, the quantitative and qualitative integration of intervention studies was limited. The five extracted studies revealed a problem with research quality. None of the evaluated studies met all six CCAR criteria. Therefore, the present results are based on the integration of poor-quality research. At the time of article selection, it was clear that few studies used RCTs or reported statistics. In the meta-analyses of research on older adults with dementia (Heyn et al., 2004) and depression (Pinquart et al., 2007), many of the included studies were of high quality. Therefore, there is substantial research in the fields of medical and mental health, and its quality is considered high. The quality of research is an important aspect in the accumulation of studies. In this study, strict inclusion and exclusion criteria were set to improve the quality of the research, which resulted in a small number of extracted papers. Additionally, in the present study, it was clarified that the well-being of healthy older adults has not been sufficiently studied compared with problems such as dementia and depression.

Moreover, the differences in the effects of the intervention programs could not be verified. Since there were only four RCTs that could be quantitatively integrated, subgroup analysis was not possible. Furthermore, since there was only one study that used an active control group, it was only possible to compare studies that used a waitlist or TAU as controls. We used one study on animal-assisted activity; however, in a meta-analysis comparing many studies on animal-assisted activity for adults (Charry-Sanchez et al., 2018), participants were classified into groups based on depression, dementia, posttraumatic stress disorder, multiple sclerosis, stroke, spinal cord injury, and schizophrenia, and healthy people were not included. We also expected life reviews and tai chi to be commonly employed psychological interventions for older adults. In fact, meta-analyses of studies using reminiscence/life reviews (Bohlmeijer et al., 2007) or tai chi (Wang et al., 2010) for older adults have been reported. However, such interventions were not found in studies that met the inclusion criteria of the present study. This is most likely because research on psychological factors in older age generally focuses on problems such as depression, isolation, and dementia. It is clear from the present study that interventions for healthy older adults are necessary, as few studies have been conducted for this purpose despite the aging of populations worldwide.

\subsection{Concepts Relating to Well-Being}

Furthermore, no studies in this systematic review used the same index for well-being. There was a tendency to use subjective well-being and life satisfaction as measures; however, QOL and self-efficacy were also used. We excluded studies that did not meet the criteria for well-being in this study because many studies reported pain and life disturbance as indicators of QOL, and anxiety and depression as indicators of well-being. Studies on well-being have pointed out that it is difficult to accumulate research because measurement concepts and indices differ from study to study (Sin \& Lyubomirsky, 2009). The same tendency was observed in the present study. Almost all of the studies measured well-being as a secondary outcome rather than a primary outcome. For healthy people, it is necessary to promote positive aspects of mental health, such as well-being, rather than negative aspects, such as depression. In particular, for preventive interventions, increasing positive 
biopsychosocial resources is important. Therefore, it is necessary to conduct intervention studies for healthy older adults and practical studies that focus on improving well-being in the future. From the results of the present study, it is clear that research has not progressed sufficiently in terms of quality, measurement indices, or theory. As lifestyles and biological functions change with age (Hultsch et al., 1999), it may be necessary to generate a theory of well-being in older adults and conduct high-quality research that can be integrated to gain a comprehensive perspective.

\subsection{Limitations and Future Directions}

The results of the present study clarified that few studies have addressed well-being in healthy older adults. Only five studies were included in the qualitative integration, and their overall quality was low. The small number of evaluated studies is probably because research on well-being in healthy older adults has not received much attention from an exclusively psychological intervention perspective to date. There is an accumulation of high-quality research on dementia and loneliness in older adults (Heyn et al., 2004); however, from the viewpoint of health promotion and preventive interventions, it is considered necessary to study well-being in healthy older adults. All five studies were conducted in different countries. For example, Rantanen et al. (2014) was conducted in Finland, and outdoor activities are an important activity in Scandinavia. Saito et al. (2012) is a study conducted in Japan, but the demographic change in the region was significant due to the declining birth rate in Japan, and local cities tended to encourage migrants to move their residential areas in their old age. Although it is impossible to say for sure at this point, we may need to consider regional and cultural characteristics when considering the well-being of the elderly.

The limitations of this study were as follows: (1) the quality of the studies was low and the number of studies was small; (2) there were few types of interventions and heterogeneity was high; (3) the outcome indicators were not uniform; (4) the effects of each intervention could not be compared; (5) publication bias was present; and (6) there was no established theory.

Therefore, there is a limit to the availability of sufficient evidence. However, improving the well-being of healthy older adults is a meaningful effort, and through a meta-analysis, this study showed that psychological interventions can be effective in this regard. Additionally, we were able to summarize interventions that improve well-being in healthy older adults. In addition, there is no reliable method for searching keywords; however, in future, words such as "aging" and "gerontology" could be used as search terms in addition to the ones used here. Furthermore, this study was limited to healthy elderly people over 65 years of age. The results may be different if the study population was under 65 years old, or if the study population was unhealthy elderly, such as those who are frail. Despite these limitations, this study can still serve as the basis for conducting higher-quality research when considering interventions for healthy older adults.

Funding This study was supported by a research grant from the Japan Society for the Promotion of Science (KAKENHI grant number JP20K14188).

\section{Declarations}

Conflict of interest The authors declare that they have no conflicts of interest. 
Open Access This article is licensed under a Creative Commons Attribution 4.0 International License, which permits use, sharing, adaptation, distribution and reproduction in any medium or format, as long as you give appropriate credit to the original author(s) and the source, provide a link to the Creative Commons licence, and indicate if changes were made. The images or other third party material in this article are included in the article's Creative Commons licence, unless indicated otherwise in a credit line to the material. If material is not included in the article's Creative Commons licence and your intended use is not permitted by statutory regulation or exceeds the permitted use, you will need to obtain permission directly from the copyright holder. To view a copy of this licence, visit http://creativecommons.org/licenses/by/4.0/.

\section{References}

Alexopoulos, G. S. (2005). Depression in the elderly. The Lancet, 365(9475), 1961-1970. https://doi. org/10.1016/S0140-6736(05)66665-2

Blanchflower, D. G., \& Oswald, A. J. (2008). Is well-being U-shaped over the life cycle? Social Science \& Medicine, 66(8), 1733-1749. https://doi.org/10.1016/j.socscimed.2008.01.030

Bohlmeijer, E., Roemer, M., Cuijpers, P., \& Smit, F. (2007). The effects of reminiscence on psychological well-being in older adults: A meta-analysis. Aging \& Mental Health, 11(3), 291-300. https:// doi.org/10.1080/13607860600963547

Bolier, L., Haverman, M., Westerhof, G. J., Riper, H., Smit, F., \& Bohleijer, E. (2013). Positive psychology interventions: A meta-analysis of randomized controlled study. BMC Public Health, 13(1), 119. https://doi.org/10.1186/1471-2458-13-119

Bray, I., \& Gunnell, D. (2006). Suicide rate, life satisfaction and happiness as markers for population mental health. Social Psychiatry \& Psychiatric Epidemiology, 41(5), 333-337. https://doi.org/10. 1007/s00127-006-0049-z

Charry-Sanchez, J. D., Pradilla, I., \& Talero-Gutierrez, C. (2018). Animal-assisted therapy in adults: A systematic review. Complementary Therapies in Clinical Practice, 32, 169-180. https://doi.org/10. 1016/j.ctcp.2018.06.011

Cho, J., Martin, P., Poon, L. W., The Georgia Centenarian Study. (2015). Successful aging and subjective well-being among oldest-old adults. The Gerontologist, 55(1), 132-143. https://doi.org/10. 1093/geront/gnu074

Colombo, G., Buono, M. D., Smania, K., Raviola, R., \& De Leo, D. (2006). Pet therapy and institutionalized elderly: A study on 144 cognitively unimpaired subjects. Archives of Gerontology and Geriatrics, 42(2), 207-216. https://doi.org/10.1016/j.archger.2005.06.011

Cristea, I. A., Huivers, M. J. H., David, D., Hollon, S. D., Andersson, G., \& Cuijpers, P. (2015). The effects of cognitive behavior therapy for adult depression on dysfunctional thinking: A meta-analysis. Clinical Psychology Review, 42, 62-71. https://doi.org/10.1016/j.cpr.2015.08.003

De Leo, D., Cleiren, M. P. H. D., \& Diekstra, R. F. W. (1995). LEIPAD-short version (SV), a short instrument to measure self-perceived functions and well-being in the elderly. University of Leiden Publication.

Dickens, A. P., Richards, S. H., Greaves, C. J., \& Campbell, J. L. (2011). Interventions targeting social isolation in older people: A systematic review. BMC Public Health, 11(1), 647. https://doi.org/10. 1186/1471-2458-11-647

Folkman, S. (1997). Positive psychological states and coping with severe stress. Social Science and Medicine, 45, 1207-1221. https://doi.org/10.1016/S0277-9536(97)00040-3

Gallo, J. J., Anthony, J. C., \& Muthén, B. O. (1994). Age differences in the symptoms of depression: A latent trait analysis. Journal of Gerontology, 49(6), 251-264. https://doi.org/10.1093/geronj/49.6. $\mathrm{P} 251$

Garber, C. E., Greaney, M. L., Riebe, D., Nigg, C. R., Burbank, P. A., \& Clark, P. G. (2010). Physical and mental health-related correlates of physical function in community dwelling older adults: A cross sectional study. BMC Geriatrics, 10(1), 6. https://doi.org/10.1186/1471-2318-10-6

Hedges, L. V. (1981). Distribution theory for Glass's estimator of effect size and related estimators. Journal of Educational Statistics, 6(2), 107-128. https://doi.org/10.2307/1164588

Heyn, P., Abreu, B. C., \& Ottenbacher, K. J. (2004). The effects of exercise training on elderly persons with cognitive impairment and dementia: A meta-analysis. Archives of Physical Medicine and Rehabilitation, 85(10), 1694-1704. https://doi.org/10.1016/j.apmr.2004.03.019

Higgins, J. P. T., \& Green, S. (2008). Cochrane handbook for systematic reviews of interventions. John Wiley and Sons. 
Hultsch, D. F., Hertzog, C., Small, B. J., \& Dixon, R. A. (1999). Use it or lose it: Engaged lifestyle as a buffer of cognitive decline in aging? Psychology \& Aging, 14(2), 245-263. https://doi.org/10.1037/ 0882-7974.14.2.245

International Labour Force (2021). Labour force participation rate by sex and age: ILO modelled estimates, nov. 2020. https://www.ilo.org/shinyapps/bulkexplorer0/?lang=en\&segment=indicator\&id=EAP_ 2WAP_SEX_AGE_RT_A (2020/3/1)

Iwano, S., Aoki, S., \& Sakano, Y. (2014). Relationship between the levels of psychological well-being in Japan. In Poster session presented at the 8th International Congress of Cognitive Psychotherapy.

Jørgensen, L., Paludan-Müller, A. S., Laursen, D. R. T., Savović, J., Boutron, I., Sterne, J. A. C., Higgins, J. P. T., \& Hróbjartsson, A. (2016). Evaluation of the cochrane tool for assessing risk of bias in randomized clinical trials: Overview of published comments and analysis of user practice in cochrane and non-cochrane reviews. Systematic Reviews. https://doi.org/10.1186/s13643-016-0259-8

Lamers, S. M. A., Boiler, L., Westerhof, G. J., Smit, F., \& Bohlmeijer, E. T. (2012). The impact of emotional well-being on long-term recovery and survival in physical illness: A meta-analysis. Journal of Behavioral Medicine, 35(5), 538-547. https://doi.org/10.1007/s10865-011-9379-8

Lawler-Row, K. A., \& Piferi, R. L. (2006). The forgiving personality: Describing a life well lived? Personality and Individual Differences, 41, 1009-1020. https://doi.org/10.1016/j.paid.2006.04.007

Miller, G. E., \& Cohen, S. (2001). Psychological interventions and the immune system: A meta-analytic review and critique. Health Psychology, 20(1), 47-63. https://doi.org/10.1037/0278-6133.20.1.47

Moher, D., Liberati, A., Tetzoaff, J., Altman, D. G., The PRISMA Group. (2009). Preferred reporting items for systematic reviews and meta-analyses: The PRISMA statement. Annals of Internal Medicine, 151(4), 264-269. https://doi.org/10.1371/journal.pmed.1000097

Moore, R. C., Straus, E., Dev, S. I., Parish, S. M., Sueko, S., \& Eyler, L. T. (2017). Development and pilot randomized control trial of a drama program to enhance well-being among older adults. Arts in Psychotherapy, 52, 1-9. https://doi.org/10.1016/j.aip.2016.09.007

Mountain, G., Windle, G., Hind, D., Walters, S., Keertharuth, A., Chatters, R., et al. (2017). A preventive lifestyle intervention for older adults (lifestyle matters): A randomized controlled trial. Age and Ageing, 46(4), 627-634. https://doi.org/10.1093/ageing/afx021

Netz, Y., Wu, M., Becker, B. J., \& Tenenbaum, G. (2005). Physical activity and psychological well-being in advanced age: A meta-analysis of intervention studies. Psychology and Aging, 20(2), 272-284. https:// doi.org/10.1037/0882-7974.20.2.272

Neugarten, B. L., Havighurst, R. J., \& Tobin, S. S. (1961). The measurement of life satisfaction. Journal of Gerontology, 16, 134-143. https://doi.org/10.1093/geronj/16.2.134

Onrust, S., Cuijpers, P., Smit, F., \& Bohlmeijer, E. (2007). Predictors of psychological adjustment after bereavement. International Psychogeriatrics, 19(5), 921-934. https://doi.org/10.1017/S104161020 6004248

Pinquart, M., Duberstein, P. R., \& Lyness, J. M. (2007). Effects of psychotherapy and other behavioral interventions on clinically depressed older adults: A meta-analysis. Aging \& Mental Health, 11(6), 645657. https://doi.org/10.1080/13607860701529635

Pinquart, M., \& Sörensen, S. (2000). Influences of socioeconomic status, social network, and competence on subjective well-being in later life: A meta-analysis. Psychology and Aging, 15(2), 187-224. https:// doi.org/10.1037/0882-7974.15.2.187

Rantanen, T., Äyräväinen, I., Eronen, J., Lyyra, T., Törmäkangas, T., Vaaraman, M., et al. (2014). The effect of an outdoor activities' intervention delivered by older volunteers on the quality of life of older people with severe mobility limitations: A randomized controlled trial. Aging Clinical and Experimental Research, 27(2), 161-169. https://doi.org/10.1007/s40520-014-0254-7

Saito, T., Kai, I., \& Takizawa, A. (2012). Effects of a program to prevent social isolation on loneliness, depression, and subjective well-being of older adults: A randomized trial among older migrants in Japan. Archives of Gerontology and Geriatrics, 55(3), 539-547. https://doi.org/10.1016/j.archger.2012. 04.002

Schwarzer, R., \& Jerusalem, M. (1995). Generalized self-efficacy scale. In J. Weinman, S. Wright, \& M. Johnston (Eds.), Measures in health psychology: A user's portfolio causal and control beliefs (pp. 35-37). NFER-Nelson.

Sin, N. L., \& Lyubomirsky, S. (2009). Enhancing well-being and alleviating depressive symptoms with positive interventions: A practice-friendly meta-analysis. Journal of Clinical Psychology, 65(5), 467-487. https://doi.org/10.1002/jclp.20593

Skevington, S. M., Lotfy, M., \& O'Connell, F. A. (2004). The World Health Organization's WHOQOLBREF quality of life assessment: Psychometric properties and results of the international field trial. A report from the WHOQOL group. Quality of Life Report, 13(2), 299-310. 
Strawbridge, W. J., Deleger, S., Roberts, R. E., \& Kaplan, G. A. (2002). Physical activity reduces the risk of subsequent depression for older adults. American Journal of Epidemiology, 156(4), 328-334. https:// doi.org/10.1093/aje/kwf047

Tinkler, I., \& Hicks, S. (2011). Measuring subjective well-being. Office for National Statistics.

United Nations. (1956). The aging of populations and its economic and social implications. United Nations Publication.

United Nations. (2020). World population prospects 2019: Highlights. United Nations Publications.

Wang, C., Bannuru, R., Ramel, J., Kupelnick, B., Scott, T., \& Schmid, C. H. (2010). Tai chi on psychological well-being: Systematic review and meta-analysis. BMC Complementary \& Alternative Medicine, 10(1), 23. https://doi.org/10.1186/1472-6882-10-23

Warr, P., Butcher, V., Robertson, I., \& Callinan, M. (2004). Older people's well-being as a function of employment, retirement, environmental characteristics and role preference. British Journal of Psychology, 95, 297-324. https://doi.org/10.1348/0007126041528095

Wiktorsson, S., Funeson, B., Skoog, I. S., Östling, S., \& Waern, M. (2010). Attempted suicide in the elderly: Characteristics of suicide attempters 70 years and older and general population comparison group. American Journal of Geriatric Psychiatry, 18(1), 57-67. https://doi.org/10.1097/JGP.0b013e3181 bd1c13

Witvliet, C. V. O., \& Vrana, S. R. (1995). Psychophysiological responses as indices of affective dimensions. Psychophysiology, 32, 436-443. https://doi.org/10.1111/j.1469-8986.1995.tb02094.x

World Health Organization. (2013). Mental health action plan 2013-2020. World Health Organization.

Wright, T. S., \& Cropanzano, R. (2000). Psychological well-being and job satisfaction as predictors of job performance. Journal of Occupational Health Psychology, 5(1), 84-94. https://doi.org/10.1037/10768998.5.1.84

Yokomitsu, K., Irie, T., Saito, R., Matsuoka, H., \& Sakano, Y. (2014). Effectiveness of cognitive behavioral therapy for pathological gambling: A meta-analysis. Japanese Journal of Behavior Therapy, 40(2), 95-104.

Publisher's Note Springer Nature remains neutral with regard to jurisdictional claims in published maps and institutional affiliations. 